\title{
Research on Student Management of Higher Vocational Colleges Based on Mobile WeChat Mini Program
}

\author{
Li Junfei ${ }^{1, a^{*}}$, Zhao Longhai ${ }^{2, b}$, \\ ${ }^{1}$ Department of Information Engineering, Shanwei Polytechnic, Shanwei, Guangdong province, China \\ ${ }^{2}$ Department of Information Engineering, Shanwei Polytechnic, Shanwei, Guangdong province, China \\ a*lijunfei@jssvc.edu.cn \\ ${ }^{b}$ tianjin02@126.com
}

\begin{abstract}
With the changes of teachers and students, the student management of higher vocational colleges in China is facing some new problems. This article analyzes the problems faced by the managers today, introduces the characteristics of WeChat Mini Program, and explores and practices the application of WeChat Mini Program in the management of higher vocational students which is of a certain reference significance and value.
\end{abstract}

Keywords: Higher vocational colleges, Student management, WeChat Mini Program

\section{INTRODUCTION}

The grassroots work of student management in higher vocational colleges is mainly the work of counselors and class teachers, which is based on certain social, political and economic development needs, centered on specific school-running guiding ideologies and talent training models, and follows the laws of physical and mental development of students, provides services for the growth, talent and development of the company.

\section{THE MANAGEMENT OF STUDENTS IN HIGHER VOCATIONAL COLLEGES IS FACING MANY PROBLEMS IN CHINA}

\subsection{More Difficult in Manage}

With the continuous expansion of Chinese colleges and universities, the quality of students in higher vocational colleges is also rapidly declining. Some schools have implemented enrollment in order to obtain students, and the learning ability and cultural quality of students are getting lower and lower.

Most vocational students are generally tired of studying, and some come to school at the request of their parents. These students were perfunctory to their studies after they got rid of their parents' control and supervision. They often arrived late for class and quit early. In addition, most Chinese students nowadays are only children, with strong personalities, strong individualism, weak sense of dedication and collective honor.[1]

\subsection{Few Student Management Staff}

Nowadays, due to the small number of counselors in higher vocational colleges, most of the professional teachers are in charge of the work of the class teacher.

At present, the teaching reform of higher vocational colleges is very strong, and the teaching requirements of professional teachers are high. They must not only have systematic professional theoretical knowledge, but also a certain enterprise practical ability. They must continue to learn new teaching methods with teaching more than ten lessons per week. For so many requirements, it is not easy for professional teachers to do well in class, which will inevitably lead to a decline in the quality of student management work they undertake.

In addition, professional teachers generally have not systematically studied psychology, pedagogy and management, they don't have opportunities to be trained in various student management tasks like counsellors. Therefore, they lack work skills and work experience in dealing with students' ideological and psychological dynamics and internal contradictions in the class. 


\subsection{Complex work objects}

The objects in the management of students are complex. From the inside of the school, there are not only students, but also all departments related to students, such as the Student Office, the Youth League Committee, the Finance Office, the Security Office, the Logistics Office, and the Dormitory Management Center. From a social point of view, student management will involve many companies which for both expanding the employment market of students and understand the situation of student internships.[2]

\subsection{Tedious Work Content}

Student management work goes deep into all aspects of students, from psychological counseling to career counseling, from scholarship selection to accident handling, from classroom attendance to dormitory management, from the construction of Party and League work to the improvement of students' comprehensive quality, etc, which put forward high requirements on the quality and working methods of the student management staff.

\subsection{Communication With Students' Families}

It is generally believed that college students should have good self-discipline ability without communicating with their parents. For today's vocational students in China, it is often difficult to carry out student management without the link of communicating with parents.

Under China's school management system, student administrators are the first to be held accountable by the school and the student's parents if something goes wrong. In this situation, it is very necessary to increase the connection with the parents of the students for student administrators to achieve the unity of home and school and promot the growth of students.[3]

\subsection{Timeliness of Student Management}

The timeliness of student management is very demanding, for so many different and complex jobs, management personnel cannot fully grasp the information of each student, nor can fully understand the work effect, which brings some challenges to the work. It is necessary for student administrators to actively adapt to these requirements, continue to innovate work with information technology and explore new management modes at this stage.

\section{ANALYSIS OF WECHAT MINI PROGRAMS ON MOBILE}

With the rapid development of smart phones, students and teachers are now focusing more on mobile phones, which provides a foundation for the development of mobile WeChat Mini Programss in student management.[4]

\subsection{Technical Analysis of Mobile Terminal Construction}

The mobile terminal construction mainly includes two ways: Native APP and Web APP.[5]

The biggest feature of Native APP development model is that it is highly dependent on the operating system of the mobile phone. Apps deployed on different mobile operating systems need to be developed with different development tools. When users need to use an APP, they must download the corresponding APP application, and then install it on the phone before using it.

Web APP refers to the system and application based on Web, when users use it, they don't need to download the APP, just use the browser to open the corresponding website to get the corresponding service or function.

The advantages of Native APP: fast running speed, less network resources.

The advantages of Web APP: supporting different mobile terminal operating systems, no upgrade required.

The disadvantage of Native APP: need to download, install and upgrade before use.

The disadvantage of Web APP: depend on the browser during use

\section{2. the Characteristics of WeChat Mini Programs}

On January 9, 2017, the WeChat Mini Program was officially launched. At present, well-known applications in many fields have launched corresponding Mini Programs. [6]

WeChat applet has many advantages. With these advantages, coupled with the high share of WeChat in mobile applications, the application of WeChat applet is becoming more and more popular.

\subsubsection{User-friendly}

The WeChat Mini Program is based on the WeChat application which conforms to the users' operating habits. The operating of the applet is as convenient and concise as using the Native APP.

\subsubsection{Low Cost}

Generally, the development of a single-function Native APP or Web APP requires an investment of at least 100,000 RMB, while the WeChat applet adopts 
newly defined specifications, and the general development investment is tens of thousands of RMB.

\subsubsection{Easy to Use}

At present, what bothers us is that a large number of APPs must be installed in the mobile phone. These APPs occupy a large amount of storage space and screen space of the mobile phone and affect our normal experience.

The biggest feature of WeChat Mini Programs is "light and fast". It puts forward a concept that users can use it without downloading and installing, which realizing the dream of application "at your fingertips".

Users of WeChat Mini Programs do not have to consider whether to install too many applications, applications will be ubiquitous and available anytime, anywhere.

The WeChat applet is based on WeChat APP, so its resource scheduling depends on WeChat. It combines the advantages of Native APP and Web APP, which has a good development prospect.

\section{THE PROS AND CONS OF USING WECHAT MINI PROGRAMS FOR THE MANAGEMENT OF STUDENTS IN HIGHER VOCATIONAL COLLEGES}

\subsection{Advantages}

High vocational college students have a high usage rate of smartphones and $\mathrm{WeChat}$. By the application of WeChat applets, student management staff can learn about students' dynamics in a timely manner, fully grasp the situation of students, and break through the limitations of time and space. [7]

The use of WeChat applets can deliver messages more conveniently and improve work efficiency.

The proposal of the "Internet +" strategy has brought opportunities for the use of WeChat Mini Programs in the management of students in higher vocational colleges. With the continuous enrichment and improvement of the functions of WeChat Mini Programs, its prospects of using will be very good.[8]

\subsection{Disadvantages}

Higher vocational students' excessive addiction to smart phones may affect their own learning, and some functions in smart phones will infringe on students' privacy.[9]

The use of WeChat Mini Programs requires student work managers of higher vocational colleges to continuously innovate application forms, flexibly use its various functions, and keep pace with the times in combination with the characteristics of contemporary higher vocational students.[10]

\section{EXPLORATION AND PRACTICE}

The authors of this article take the local vocational colleges which they work as a sample, and take the parttime class teacher work as an example., develop applications through WeChat applet, and integrates the class teacher, students and students' parents into the daily management work for empirical research and exploration.

The WeChat applet designed mainly implements the following functional sections.

\subsection{Class Homepage}

There are class photos, class theme dreams, class audio and video display, which for enhancing class cohesion, and leting students' parents understand the class.

\subsection{Display of Class Committee}

There are contents such as a group photos of the class committee, a personal profile of the class committee, and an introduction to the division of labor.

\subsection{Display of Class Members}

There are personal photos, personal strengths, personal dreams and declarations, and the work of the clubs and departments they have joined, which show students' personal abilities and youthful vitality.

\subsection{Introduction of The Dormitory}

There are a group photos of each dormitory, consisting of living environment, learning display, dormitory declaration, which for enhancing the sense of collective honor of each dormitory.

\subsection{Class Documents}

Release daily documents and daily notices related to the school, students and class management.

\subsection{Daily Assessment}

Release students' daily attendance, which including lateness, early leaving, absenteeism, leave and etc., also release weekly hygiene scores of each dormitory, student test scores, so students' parents can understand the students' learning and living conditions at school.

\subsection{Display of Student Activities}

Publish photos and descriptions of various activities of the class, departments, and campuses that students 
participate in, such as theme class meetings, public welfare labor, sports games, campus singer competitions, etc., so that students' parents can understand the students' school participation in activities.

\subsection{Interactive communication}

Provide the function of interactive communication between students, parents and class teachers.

Students are responsible for real-time updates of each functional section.

\section{CONCLUSION}

After the WeChat applet was created and officially launched, students were initially asked to notify their parents to pay attention, but this encountered considerable resistance.

Most students can promote this WeChat Mini Program to their parents and are willing to share their performance in school with their parents.

However, a small number of students who do not like to study and are often late or absent from school are very resistant to the WeChat Mini Program, because once their parents know the WeChat Mini Program with regular attention, their various bad performances and behaviors in the school will be known by their parents in real time, and their parents will monitor them.

After a year of trial, the application of the WeChat applet has achieved some results. Some students' parents pay great attention to using the WeChat applet to understand the situation of the class and their children's performance in school in real time, who gradually become accustomed to using this WeChat applet to supervise their children. If the content in the WeChat applet is not updated in time, and some parents will call to ask why.

This WeChat Mini Program has established a bridge between the class teacher, students and students' parents, and has played a positive role in class management.

By the use of the WeChat Mini Program, it is proved that the use of the WeChat Mini Program can better support the work of the student management staff of higher vocational colleges, which conform to the needs of the times and technological development, and can improve work efficiency.

The use of WeChat Mini Programs can not only adapt to the needs of the "Internet + " era, but also conform to the characteristics of students in higher vocational colleges. The work in this thesis has certain reference value for student management and school development in higher vocational colleges.

\section{REFERENCES}

[1] Li Yuzhen, Xiao Huaiqiu. Problems and countermeasures in the work of part-time head teachers in higher vocational colleges, Jiangxi Chemical Industry, vol. 5, 2016, pp. 136-137.

[2] Chen Feng, Ren Yongmei. Analysis of the problems and countermeasures in the daily work of head teachers in higher vocational colleges, science and technology vision, vol. 1, 2017, pp. 271-272.

[3] Dai Zimeng, Liu Shanshan, Song Huiqian. Research on the Work of College Counselors Based on WeChat, Academic Weekly, vol. 11, 2018, pp. 10-11.

[4] Zhao Hui. Application development of campus APP based on mobile phone platform, social science theory, vol. 16, 2016, pp. 160-161.

[5] Fang Renfu. Discussion on WeChat-based mobile smart campus construction plan, science and technology vision, vol. 31, 2015, pp. 208.

[6] Jin Yujun, Jiang Xiaotong, Kuang Yinghui. Application of MINA framework based on highperformance NIO, China Science and Technology Information, vol. 16, 2009, pp. 93-94.

[7] Feifei Pei. The innovation of WeChat in the work of college counselors, modern economic information, vol. 12,2017 , pp. 210-211.

[8] Li Yanchao. The application of WeChat in the work innovation of college counselors, Journal of Yanbian Education College, vol. 4, 2016, pp. 99100.

[9] Liu Hongwei. Analysis of WeChat Mini Program Application, Wireless Internet Technology, vol. 23, 2016, pp. 11-12.

[10] Chen Jun, Wu Bing, Wang Jinsen. Analysis of the application status and prospects of WeChat applets in libraries, new campus, vol. 10, 2017, pp. 59 60. 